Raziyeh Kheshtzar, Aydin Berenjian*, Seyedeh-Masoumeh Taghizadeh, Younes Ghasemi, Ali Ghanbari Asad and Alireza Ebrahiminezhad*

\title{
Optimization of reaction parameters for the green synthesis of zero valent iron nanoparticles using pine tree needles
}

https://doi.org/10.1515/gps-2019-0055

Received December 16, 2018; accepted July 02, 2019.

Abstract: In the current study, the optimal reaction condition for fabrication of INPs by using pine tree (Pinus eldarica) leaf extract was developed. A fractional factorial design was utilized to screen the effective parameters in the green synthesis reaction, and central composite face design was employed to achieve the optimal reaction condition. Leaf extract and iron precursor concentrations were found to be the most effective parameters for the fabrication of INPs. Physicochemical characteristics of the obtained nanoparticles were evaluated by transmission electron microscopy (TEM), Fourier transform infrared (FTIR) spectroscopy, $\mathrm{X}$-ray diffractometer (XRD), vibrating sample magnetometer (VSM), thermogravimetric analysis (TGA), and derivative thermo gravimetric (DTG). The prepared particles were found to be zero-valent iron nanoparticles without any iron oxide impurities. Nanoparticles were spherical in shape with diameters ranging from $8 \mathrm{~nm}$ to $34 \mathrm{~nm}$ with a mean particle size of $18 \mathrm{~nm}$. The fabricated particles were amorphous with a low magnetization value of $33 \mathrm{memu} / \mathrm{g}$.

\footnotetext{
* Corresponding authors: Aydin Berenjian, School of Engineering, Faculty of Science and Engineering, University of Waikato, Hamilton, New Zealand, e-mail: aydin.berenjian@waikato.ac.nz;

Alireza Ebrahiminezhad, Department of Medical Nanotechnology, School of Advanced Medical Sciences and Technologies, Shiraz University of Medical Sciences, Shiraz, Iran; Department of Medical Biotechnology, School of Medicine, and Noncommunicable Disease Research Centre, Fasa University of Medical Sciences, Fasa, Iran; Department of Pharmaceutical Biotechnology, School of Pharmacy and Pharmaceutical Sciences Research Center, Shiraz University of Medical Sciences, Shiraz, Iran, e-mail: a_ebrahimi@sums.ac.ir

Raziyeh Kheshtzar and Ali Ghanbari Asad, Department of Medical Biotechnology, School of Medicine, and Noncommunicable Disease Research Centre, Fasa University of Medical Sciences, Fasa, Iran Seyedeh-Masoumeh Taghizadeh and Younes Ghasemi, Department of Pharmaceutical Biotechnology, School of Pharmacy and Pharmaceutical Sciences Research Center, Shiraz University of Medical Sciences, Shiraz, Iran
}

Keywords: biosynthesis; design of experiments (DoE); plant mediated synthesis; optimization; response surface methodology (RSM)

\section{Introduction}

Iron nanoparticles (INPs) due to their unique physicochemical and biological characteristics are one of the most applied nanostructures in the science and technology. These nanoparticles are now employed in a variety of applications ranging from environmental remediation to biomedicine and pharmaceutical sciences [1-10]. Over the last decade, several chemical and physical techniques were developed for the synthesis of INPs. Due to intrinsic limitations and problems of these techniques, several attempts have been made to find out a sustainable approach for the synthesis of INPs [11,12]. Green synthesis has emerged as a promising approach in this regard. Due to employing natural compounds from plants or microorganisms, this method has significant advantages over the physical and chemical procedures [13-18]. However, there are still some difficulties with employing microorganisms for the synthesis of nanostructures $[19,20]$.

Thanks to plant mediated green synthesis, fabrication of nanostructures is now possible in a facile, economic, and environmental friendly manner without any elaborate and complicated procedures [6,16,17,21-23]. Plant extract mediated synthesis owing to simple processing and cheap raw materials provides a suitable opportunity for biosynthesis of nontoxic and biocompatible nanoparticles [24]. Plant extracts contain phytochemicals such as polyphenols, flavonoids, reducing sugars, proteins, carbohydrates, nitrogen bases, and amino acids that can act as reducing and capping agents for converting metal ions to metal nanoparticles and stabilizing them $[6,16,17,22,23]$. So far, variety of plants such as green tea, Syzygium cumini, Eucalyptus, Cupressus sempervirens, Hordeum vulgare, stinging nettle (Urtica dioica), Mediterranean cypress 
(Cupressus sempervirens), and Rumex acetosa have been used to produce INPs $[1,6,8,11,16,21,25,26]$. However, there are limited data available about the effective factors in the green synthesis of nanoparticles and the optimal reaction conditions [22,23,25,27,28]. Meanwhile, knowledge about the effective parameters in the reaction process and optimal reaction condition is the critical point to achieve higher productivity. These data can be achieved successfully by using a design of experiment software which less employed for the plant mediated synthesis of nanoparticles.

Pinus eldarica (also known as Pinus brutia var. eldarica, calabrian pine, mondell pine, and Eldarian pine) is a very famous tree of the Pinaceae family with evergreen foliage. It height can be about 9-25 m and usually found with brown or green cones. Pine tree adapted to survive in wide range of climates, so can be found in many regions of world. Furthermore, it is native to Iran, Iraq, Armenia, Azerbaijan, and Georgia. This tree has gained medical applications for treating hyperlipidemia, atherosclerosis, nerve malfunction, neuralgic disorders and rheumatism. The needle leaves of the tree are source of natural compounds such as polyphenols, antioxidants, proanthocyanidins, luteins, and beta-carotene that are key elements in the green synthesis of metal nanoparticles [29-32]. However, bark extract of this tree was just used for the green synthesis of silver nanoparticles [27]. Therefore, in the present study the potential application of pine tree needles extract for production of INPs were investigated. The effective factors in the synthesis reaction and optimal reaction condition for highest rate of nanoparticles production were also demonstrated by using design of experiments (DoE) and response surface methodology (RSM), respectively [33-35].

\section{Materials and methods}

\subsection{Materials}

Pinus eldarica needle leaves were collected from garden campus of the Fasa university of Medical sciences (Fasa, Fars province, Iran). Ferric chloride $\left(\mathrm{FeCl}_{3} \cdot 6 \mathrm{H}_{2} \mathrm{O}\right)$ was purchased from Merck Chemicals (Darmstadt, Hessen, Germany). Millipore water (Millipore Corp., Bedford, MA, USA, conductivity range of 0.055-0.294 $\mu \mathrm{S} / \mathrm{cm}$ ) was used for all the experiments.

\subsection{Leaf extract preparation}

Needle leaves were rinsed with deionized water in order to remove possible dusts and mud particles. The needles were dried at room temperature under dust free condition for about two weeks and then powdered with household miller and passed through a particular mesh sieve. Five gram of leaves powder was mixed with $100 \mathrm{~mL}$ deionized water in a $250 \mathrm{~mL}$ round bottom flask [36,37]. The mixture was heated up to boiling by using a heater mantel under reflux. After $15 \mathrm{~min}$ boiling resultant extract was cooled to room temperature and filtered through a Whatman filter paper (Reeve angel, Grade 201) to remove the sludge. The filtrate was centrifuged ( $5000 \mathrm{rpm}, 12 \mathrm{~min}$ ) to remove fine leaf particles. A clear supernatant was obtained and used for further experiments.

\subsection{Experimental design}

The MODDE software version 9 (Umetrics, Sweden) as a tool for statistical design of experiment was employed with two predominant stages in order to optimize the factors involved in synthesis process for maximizing the production of INPs. First stage was carried out to specify the important factors with significant effects on the amount of synthesized nanoparticles. A fractional factorial design was utilized to screen the effect of four variables namely plant extract quantity, iron precursor concentration, reaction temperature, and reaction time.

Second stage was carried out to achieve an empirical model to specify the optimum concentrations of selected efficient factors. In this step, central composite face (CCF) design and RSM were used to optimize the effective factors selected from screening stage. The variables and their range of values are depicted in Table 1.

\subsection{Synthesis of INPS}

For INPs fabrication, leaf extract $(9 \mathrm{~mL})$ and deionized water $(750 \mu \mathrm{L})$ were added to a $50 \mathrm{~mL}$ round bottom flask and the mixture was stirred vigorously at room temperature. Consequently, $250 \mu \mathrm{L}$ iron precursor $\left(\mathrm{FeCl}_{3} \cdot 6 \mathrm{H}_{2} \mathrm{O}, 1 \mathrm{M}\right)$ was added to the flask and reaction was followed for $30 \mathrm{~min}$ at room temperature. The reaction product was centrifuged and resulting black precipitate was washed with deionized water for three times to remove any unreacted solutes and phytochemicals. Finally, the black pellet was oven dried at $50^{\circ} \mathrm{C}$ for $48 \mathrm{~h}$. 


\subsection{Characterization of INPs}

Physicochemical properties of the synthesized nanoparticles through optimum experiment were evaluated by material analysis techniques. Transmission electron microscope (TEM, Zeiss, EM900, HT-100 KV) studies were carried out to identify the morphology and size of the prepared particles [38-40]. Analyses were done without any sample preparation. A drop of INPs suspension was dripped on a cupper grid and dried at room temperature. Particle size analysis was conducted by using an image analysis software (ImageJ version $1.47 \mathrm{v}$, developed by NIH, http://imagejnihgov/ ij/). Fourier-transform infrared (FTIR) spectroscopy (Perkin Elmer Spectrum One) analysis was done using $\mathrm{KBr}$ pellets for characterizing the synthesized INPs and also for understanding the existence of surface functional groups on the nanoparticles. The IR absorption analysis was done from $4500 \mathrm{~cm}^{-1}$ to $400 \mathrm{~cm}^{-1}$ $[13,41]$. The crystallographic analysis of INPs was performed by X-ray powder diffractometer (Siemens D5000). Resulting XRD pattern was evaluated by X'Pert High Score version 1.0d (PAN analytical B.V., Almelo, the Netherlands) [42,43]. The magnetic properties of nanoparticles and values of magnetic parameters such as saturation magnetization $\left(\mathrm{M}_{\mathrm{s}}\right)$, coercive force $\left(\mathrm{H}_{\mathrm{c}}\right)$ and magnetic remanence $\left(\mathrm{M}_{\mathrm{r}}\right)$ were characterized using

Table 1: Experimental design and results of screening factors affecting green synthesis of INPs.

\begin{tabular}{lrrrrrr}
\hline Run & \multicolumn{4}{c}{ Experimental factors } & & Response \\
\cline { 2 - 3 } & $\begin{array}{r}\mathrm{FeCl}_{3} \\
(\mathrm{mM})\end{array}$ & $\begin{array}{r}\text { Leaf extract } \\
(\mathrm{mL})\end{array}$ & $\begin{array}{rrrrr}\text { Temperature } \\
\left.\text { ( }{ }^{\circ} \mathbf{C}\right)\end{array}$ & $\begin{array}{r}\text { Time } \\
(\mathbf{h})\end{array}$ & $\begin{array}{r}\text { Weight } \\
(\mathbf{g})\end{array}$ \\
\hline 1 & 1 & 1 & 25 & 0.5 & 0.0012 \\
2 & 50.2513 & 1 & 25 & 0.5 & 0.0015 \\
3 & 1 & 9 & 25 & 0.5 & 0.0036 \\
4 & 50.2513 & 9 & 25 & 0.5 & 0.015 \\
5 & 1 & 1 & 75 & 0.5 & 0.0001 \\
6 & 50.2513 & 1 & 75 & 0.5 & 0.0062 \\
7 & 1 & 9 & 75 & 0.5 & 0.0012 \\
8 & 50.2513 & 9 & 75 & 0.5 & 0.0207 \\
9 & 1 & 1 & 25 & 24 & 0.0026 \\
10 & 50.2513 & 1 & 25 & 24 & 0.0015 \\
11 & 1 & 9 & 25 & 24 & 0.0086 \\
12 & 50.2513 & 9 & 25 & 24 & 0.0152 \\
13 & 1 & 1 & 75 & 24 & 0.0015 \\
14 & 50.2513 & 1 & 75 & 24 & 0.012 \\
15 & 1 & 9 & 75 & 24 & 0.0144 \\
16 & 50.2513 & 9 & 75 & 24 & 0.0196 \\
17 & 25.6256 & 5 & 50 & 12.25 & 0.0132 \\
18 & 25.6256 & 5 & 50 & 12.25 & 0.015 \\
19 & 25.6256 & 5 & 50 & 12.25 & 0.0123 \\
\hline
\end{tabular}

vibrating sample magnetometer (VSM) (American-Lake Shore Cryotronics company, 7407 Model) with increasing magnetic field up to $19 \mathrm{kOe}$ and field sweeping from -19 to +19 kOe $[44,45]$. Thermo gravimetric analysis (TGA) and derivative thermo gravimetric (DTG) analyses were done by a TGA, 209 F3 Tarsus. This technique was done to determine the thermal stability, presence, and the quantification of organic compounds from Pinus eldarica leaf extract in the final INPs product. TGA thermo grams were recorded for $10.8 \mathrm{mg}$ of powder sample at a heating rate of $10^{\circ} \mathrm{C} / \mathrm{min}$ in the temperature range of 30 to $600^{\circ} \mathrm{C}$ under air atmosphere. Energydispersive X-ray spectrometer (EDS) (Rontec analyser, Germany) was employed to determine the elemental composition of nanoparticles.

\section{Results and discussion}

\subsection{Effective parameters in the synthesis reaction}

Reaction time, iron precursor concentration, leaf extract quantity, and reaction temperature were selected to investigate their effect on INPs production. DoE was carried out based on these four parameters and the amount of prepared nanoparticles was chosen as the response [35]. The results of initial screening for effective parameters in the synthesis reaction are depicted in Table 1. Table 2 illustrates the statistical analysis and variables coefficient in order to evaluate the main effects of single parameters and their interactions on the weight

Table 2: Statistical analysis and coefficients of the variables for optimal reaction condition to green synthesis of INPs.

\begin{tabular}{lrrr}
\hline Terms & Coefficient & Std. err.* & P-value \\
\hline Constant & 0.012 & 0.001 & 2.335 \\
$X_{1}$ & 0.007 & 0.002 & 0.007 \\
$X_{2}$ & 0.006 & 0.001 & 0.003 \\
$X_{3}$ & 0.003 & 0.001 & 0.064 \\
$X_{4}$ & 0.000 & 0.001 & 0.694 \\
$X_{1} \cdot X_{2}$ & 0.003 & 0.002 & 0.145 \\
$X_{1} \cdot X_{3}$ & 0.003 & 0.002 & 0.186 \\
$X_{1} \cdot X_{4}$ & 0.002 & 0.002 & 0.362 \\
$X_{2} \cdot X_{3}$ & 3.124 & 0.001 & 0.976 \\
$X_{2} \cdot X_{4}$ & 0.000 & 0.001 & 0.615 \\
$X_{3} \cdot X_{4}$ & 0.000 & 0.001 & 0.467 \\
\hline
\end{tabular}

* Std. err. $=$ Standard error, $\mathrm{X}_{1}=\mathrm{FeCl}_{3}, \mathrm{X}_{2}=$ Leaf extract, $X_{3}=$ Temperature, $X_{4}=$ Time, $R^{2}=0.841$ and $R^{2}$ (adj.) $=0.642$. 
of produced nanoparticles [34]. These results indicate that two factors namely iron precursor concentration and amount of leaf extract had significant positive effect on nanoparticles production (P-value less than 0.05 indicates that the factor is significant). These findings are in close agreement with previous report for the synthesis of iron nanoparticles using green tea extract. Where, $\mathrm{FeCl}_{3}$-to-green tea extract ratio found to be the effective parameter in the amount of nanoparticles formation [46].

\subsection{Optimization of nanoparticles production}

Determination of optimum amount for iron precursor and leaf extract to enhance the INPs production was carried out by using the central composite face (CCF) design as shown in Table 3. The ANOVA test (Table 4) indicates a good fitness of the model, because of the high $\mathrm{F}$ value of 160.421 and a very low probability value. The linear regression coefficient $\mathrm{R}^{2}=0.994$ and the adjusted

Table 3: Central composite face design matrix for the significant variables and observed response.

\begin{tabular}{lrrrr}
\hline Run & \multicolumn{2}{c}{ Experimental factors } & & Response \\
\cline { 2 - 3 } & $\mathrm{FeCl}_{3}(\mathrm{mM})$ & Leaf extract $(\mathrm{mL})$ & & Weight (g) \\
\hline 1 & 25 & 5 & 0.0033 \\
2 & 75 & 5 & 0.0036 \\
3 & 25 & 9 & 0.015 \\
4 & 75 & 9 & 0.0137 \\
5 & 25 & 7 & 0.0106 \\
6 & 75 & 7 & 0.0086 \\
7 & 50 & 5 & 0.0035 \\
8 & 50 & 9 & 0.014 \\
9 & 50 & 7 & 0.0088 \\
10 & 50 & 7 & 0.0093 \\
11 & 50 & 7 & 0.0095 \\
\hline
\end{tabular}

determination coefficient $\mathrm{R}^{2}$ of 0.988 for the model demonstrate the accuracy of the model.

The response surface plots are shown in Figure 1. Analysis of the plots demonstrates that the maximum INPs is achievable when the final concentration of iron precursor and leaf extract are set as $25-45 \mathrm{mM}$ and 8.5-9 mL, respectively. As can be seen in Figure 1, formation of nanoparticles decreases when the values of ferric chloride and leaf extract are set to be more than $50 \mathrm{mM}$ and less than $8.5 \mathrm{~mL}$, respectively. The highest productivity was predicted by the model to be $0.015 \mathrm{~g}$ per reaction (1.5 mg per $\mathrm{mL}$ of the reaction mixture) with optimum values of ferric chloride $(25 \mathrm{mM})$ and leaf extract $(9 \mathrm{~mL})$. Consequently, the validation experiment was carried out under the optimized condition which resulted in the production of $0.015 \mathrm{~g} \mathrm{~mL}^{-1} \mathrm{INPs}$.

Although vast investigations have been done in regards to green synthesis of nanoparticles, there are very rare investigations for the optimization of nanoparticles fabrication [46]. Therefore, in the present study, the effects of reaction parameters on the fabrication of INPs were investigated and the reaction condition was optimized to achieve highest amount of nanoparticles in a constant reaction volume. Reaction condition has an immense influence on the physicochemical characteristics of the green synthesized nanoparticles $[17,22,23]$. So, investigations must be done to determine the impacts of synthesis conditions and involved factors on the reactivity, morphology, and other properties of the synthesized nanoparticles. For instance, the influences of various parameters such as the ratio of iron precursor $\left(\mathrm{Fe}^{2+}\right)$ and leaf extract (tea extract), reaction temperature, and reaction $\mathrm{pH}$ were systematically investigated and have been reported by Lanlan Huang [47]. It was revealed that the reactivity of the prepared nanoparticles was highly depended to the synthesis conditions and the reduction rate is kinetically dominated by these factors.

Table 4: Analysis of variance for the fitted quadratic model

\begin{tabular}{lrrrrr}
\hline Source of variation & DF* $^{*}$ & SS $^{*}$ & MS (variance)* & Fvalue & $\boldsymbol{P v a l u e}^{*}$ \\
\hline Total & 11 & 0.001 & 9.866 & & \\
Constant & 1 & 0.000 & 0.000 & & 0.004 \\
Total corrected & 10 & 0.000 & 1.780 & & 0.005 \\
Regression & 5 & 0.000 & 3.538 & 160.421 & 0.000 \\
Residual & 5 & 1.102 & 2.205 & & 0.000 \\
Lack of fit & 3 & 8.428 & 2.809 & 2.161 & 0.332 \\
Pure error & 2 & 2.6 & 1.3 & & 0.000 \\
\hline
\end{tabular}

* DF - degree of freedom, SS - sum of squares, MS - mean sum of squares, SD - standard deviation. 

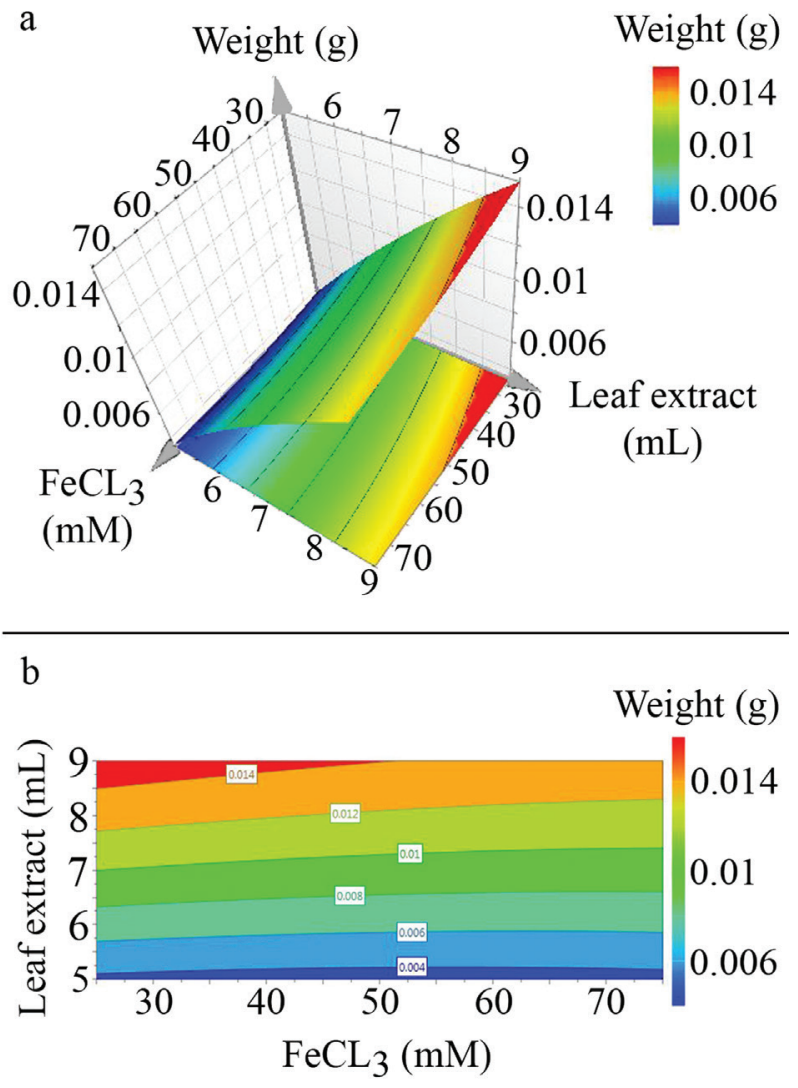

Figure 1: Response surface plot (a) and response counter plot (b) for the fabrication of INPs showing the effects of iron precursor concentration and amount of leaf extract in a green synthesis reaction, all reactions were done in $10 \mathrm{~mL}$ final volume.

\subsection{Characterization of INPs}

Physicochemical properties of the prepared INPs under optimal reaction condition were evaluated. Figure $2 \mathrm{a}$ is illustrating TEM micrograph of the produced nanoparticles and corresponding size distribution histogram is depicted in Figure $2 \mathrm{~b}$. The obtained particles were dominantly spherical in shape with $8-34 \mathrm{~nm}$ in diameter with the mean particle size of $18 \mathrm{~nm}$. Green synthesized INPs with similar particle size distribution were also reported by using a red wine, pomegranate, mulberry, and cherry leaf extract $[12,48]$. Based on the TEM micrographs, INPs were heavily surrounded by biological components from leaf extract (Figure S1), therefore, the resulting structure is a microstructure which composed of INPs and phytochemical compounds. Similar phenomenon is reported for the green synthesis of metal nanoparticles using a variety of plant extracts $[16,23,49,50]$. In some cases it has been confirmed that this biologic matrix is mainly composed of carbohydrates from leaf extract $[23,49]$.
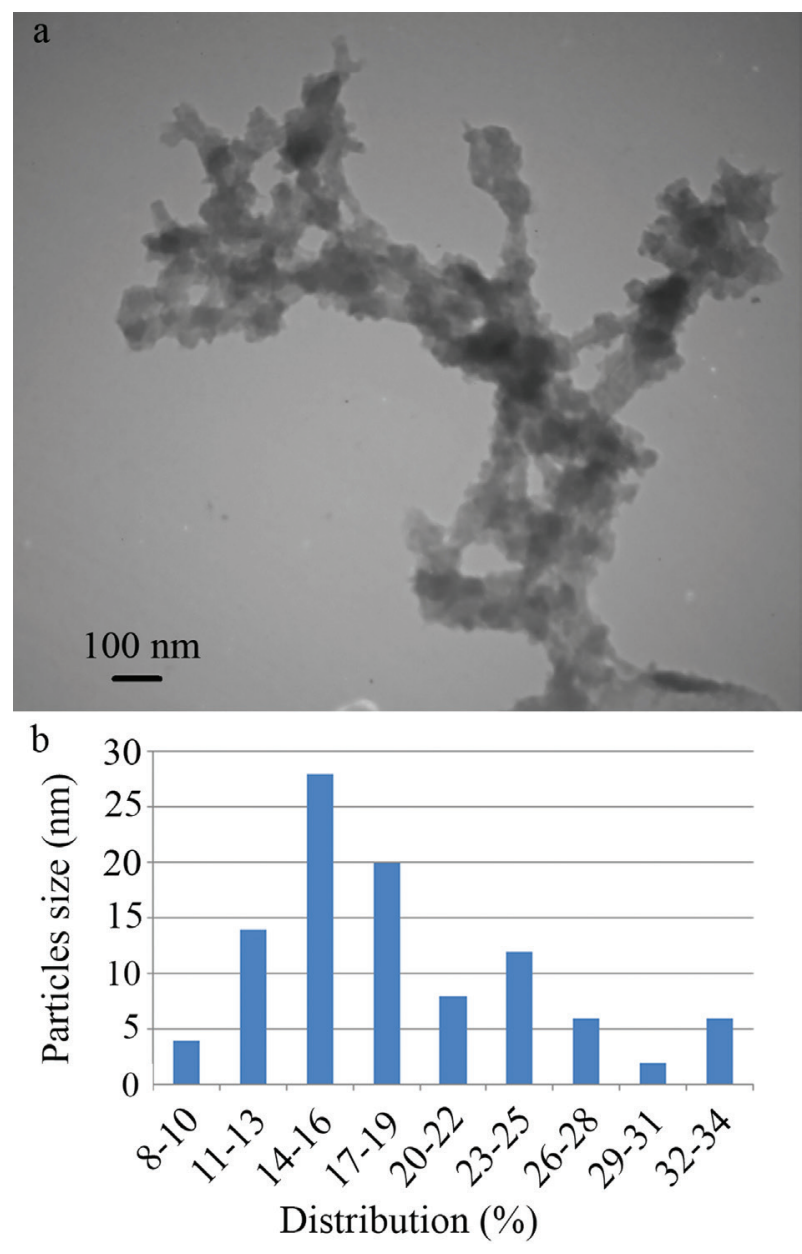

Figure 2: TEM micrograph of the biosynthesized INPs (a), which indicates that nanoparticles are spherical and surrounded by a biologic matrix from leaf extract, and corresponding particle size distribution histogram (b), more TEM image is provided in supplementary materials as Figure S1.

FTIR analysis was conducted to determine the chemical components which were responsible for stabilizing and capping of INPs. FTIR spectrum of the prepared INPs is presented in Figure 3. The $\mathrm{OH}$ groups induce a broad indicative peak which appeared at $3420.97 \mathrm{~cm}^{-1}$ [41]. The carbonyl group stretching vibration can be seen at $1616.05 \mathrm{~cm}^{-1}$ and the peak at $1069.05 \mathrm{~cm}^{-1}$ is due to $\mathrm{C}-\mathrm{O}$ bonds [41]. The peaks of aliphatic $\mathrm{C}-\mathrm{H}$ appeared around $2918 \mathrm{~cm}^{-1}$ [38-40]. The FTIR results indicate that prepared INPs are capped with biologic compounds which were derived from Pinus eldarica leaf extract $[13,22,51]$. These finding are in agreement with TEM micrograph which shows that INPs are surrounded by a biologic matrix. The Fe-O characteristic peaks of iron oxide nanoparticles commonly appear at about $640 \mathrm{~cm}^{-1}$ and $450 \mathrm{~cm}^{-1}[42-44,52,53]$. These bonds were not observed in the FTIR spectrum of the prepared particles, which is 


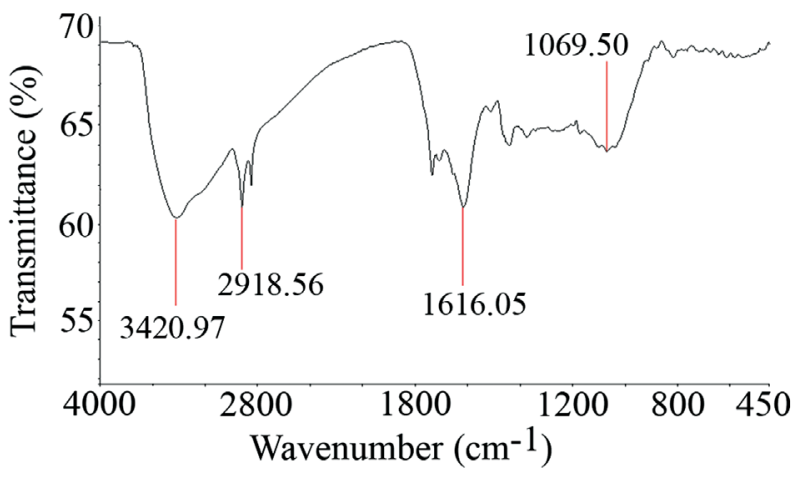

Figure 3: Fourier transform infrared (FTIR) spectra of the prepared INPs, indicating presence of organic compounds from Pinus eldarica.

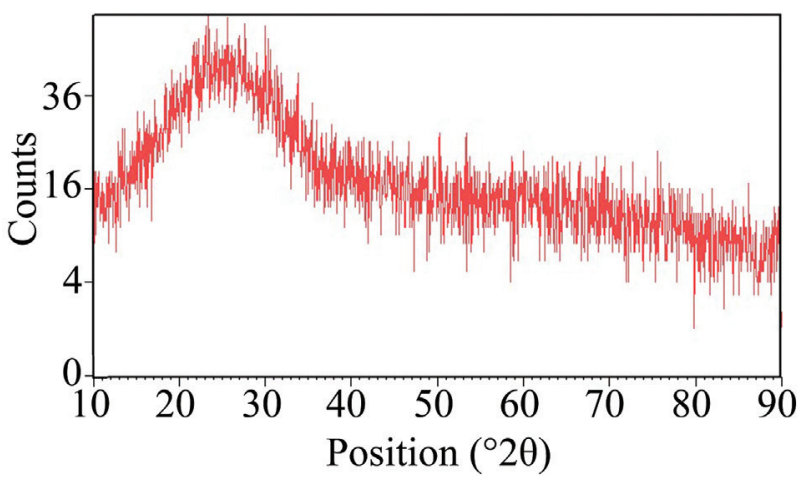

Figure 4: X-ray powder diffraction (XRD) pattern of the synthesized INPs; no characteristic peak was observed which indicates amorphous structure of the nanoparticles.

indicative of zero-valent INPs. Similar spectra were also reported for chemically or plant mediated synthesized zero-valent INPs [16,54]. Oxidation of the exposed iron atom to iron oxide/hydroxide results in a core-shell structure that $\mathrm{Fe}^{0}$ forming the core which is surrounded by an iron oxide shell $[11,55,56]$. The thin iron oxide shell lead to the appearance of Fe-O absorption bonds in the FTIR spectra, but in lower intensity than that usually observed for iron oxide nanoparticles [44]. Absence of these peaks in FTIR spectra of the prepared particles indicated the absence of iron oxide shell. Organic capping from leaf extract seems to protect the surface of zero-valent iron atoms from oxidation.

The XRD pattern of the INPs is presented in Figure 4. XRD analysis confirmed that no distinctive peaks were present on the spectra. This indicated that the INPs were not crystalline in nature and were amorphous structures. Fabrication of amorphous zero-valent INPs was also reported by using leaf extract of different plants such as eucalyptus, mulberry, pomegranate, and cherry [57]. The broad shoulder peak from $20^{\circ}$ to

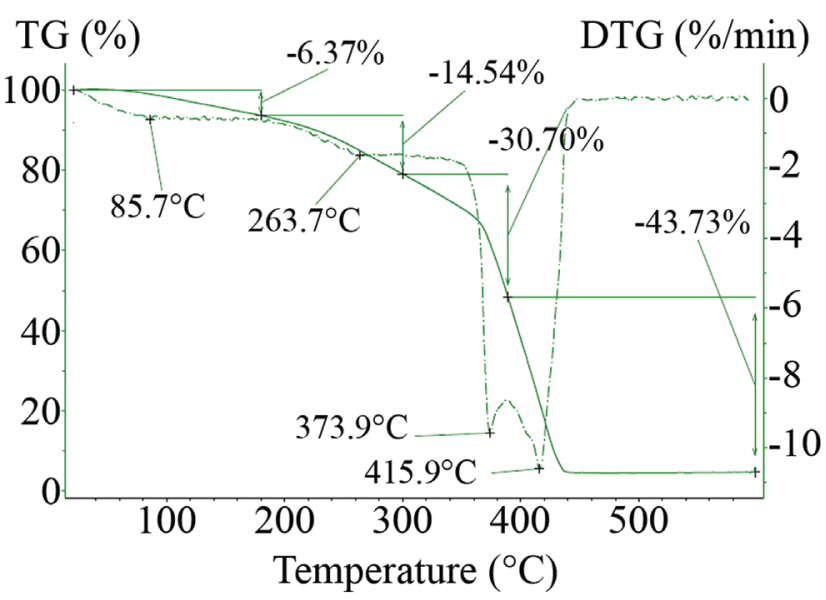

Figure 5: TGA and DTG curves of the synthesized INPs; the weight loss below $263.7^{\circ} \mathrm{C}$ was due to water evaporation and above $263.7^{\circ} \mathrm{C}$ was due to decomposition of biologic coating.

$30^{\circ}$ of $2 \theta$ values was proposed to be due to the presence of organic component from leaf extract which are responsible for capping and stabilizing nanoparticles [26]. Some researchers also considered a tinny peak appearing at around $2 \theta$ of $44-45^{\circ}$ as indicative peak for zero-valent INPs $[11,58,59]$. Production of other amorphous nanostructures was also reported for the green synthesized INPs. For instance, green synthesis of INPs by using extracts of Eucalyptus tereticornis, Melaleuca nesophila, and Rosemarinus officinalis was reported to result in amorphous iron-polyphenol nanoparticles $[4,60]$.

TGA and DTG curves of the produced INPs are provided in Figure 5, demonstrating a significant weight loss processes. The initial weight loss below $263.7^{\circ} \mathrm{C}$ should be attributed to the evaporation of residual and adsorbed water. The weight loss above $263.7^{\circ} \mathrm{C}$ corresponds to the decomposition of the capping materials $[16,61]$. Decomposition of organic materials makes the main peaks at $373.9^{\circ} \mathrm{C}$ and $415.9^{\circ} \mathrm{C}$ in the DTG curve $[16,62]$. There was no weight loss at above $440^{\circ} \mathrm{C}$. TGA analysis showed that the weight percentage of biologic coating in the product is about $74.43 \%$ [15]. Since now, the weight percentage of organic compounds in the green synthesized nanoparticles was reported to be up to $60 \%$ [63]. So, pine tree needles can be introduced as a biologic source for reducing and capping agents to provide nanoparticles with heavy coating. This unique feature can be a great advantage for future applications.

The magnetization curve as a function of the applied magnetic field at room temperature is shown in Figure 6. The sample showed no hysteresis and the 


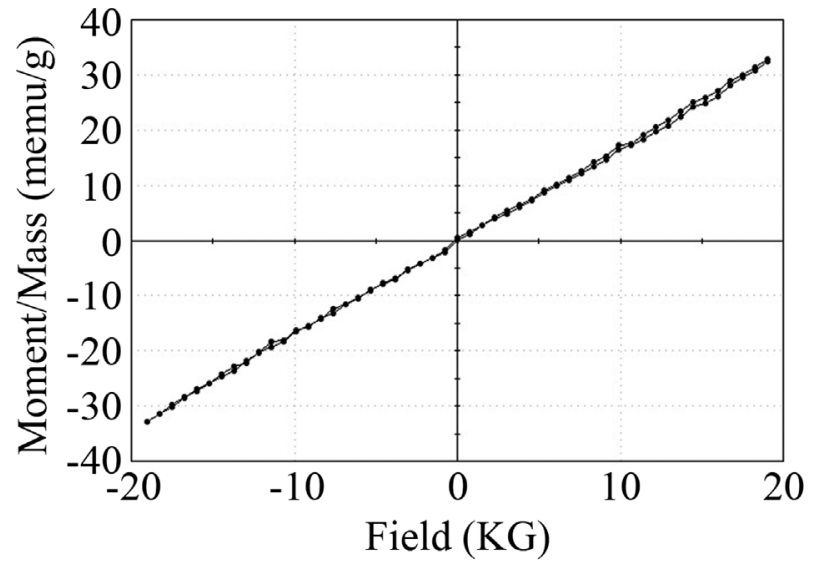

Figure 6: Magnetization curve of the prepared INPs, magnetization value of the synthesized INPs was measured to be $33 \mathrm{memu} / \mathrm{g}$.

magnetization curve was completely reversible that exhibits a superparamagnetic behavior of nanoparticles. The saturation magnetization value of the synthesized particles was found to be $33 \mathrm{memu} / \mathrm{g}$. The very low saturation value is possibly due to the diamagnetic properties of biologic capping material and amorphous state of the prepared INPs [15]. Previous investigations have indicated that increase in the intensity of biological coating resulted in significant reduction of saturation magnetization [52,53]. Also, Santra et al., reported that the magnetization of the uncoated magnetic nanoparticles $(1.3 \mathrm{emu} / \mathrm{g})$ is higher than coated nanoparticles (0.5 emu/g) [64]. In the other experiment, the saturation magnetization values of the iron nanoparticles which were synthesized by using Plectranthus amboinicus leaf extract was reported to be $1.25 \mathrm{emu} / \mathrm{g}$ [65]. Low saturation magnetization value of the prepared nanoparticles in contrast to previous report can be in agreement with TGA results which indicate a heavy biologic coating.

Localized elemental information of the iron nanoparticles was determined by EDS and results are depicted as Figure 7. There are intense peaks of C, O, Ca, and $\mathrm{Fe}$ in the spectrum and quantitative data indicated that the atomic percentages of the prepared material were $53.08 \% \mathrm{C}$, $44.76 \% \mathrm{O}, 0.30 \% \mathrm{Ca}$, and $1.87 \% \mathrm{Fe}$. The high percentage of carbon and oxygen elements originated mainly from the polyphenol groups and other C, O-containing compounds in Pinus eldarica extract. Also, Ca element is attributed to the plant extract. As can be observed from the TEM graph, the produced iron nanoparticles were heavily surrounded by biologic compounds from leaf extract, which is accountable for the low iron content in the sample. These results are in agreement with previous findings for the green synthesized INPs $[57,58,66]$. But, in comparison, the low Fe weight percent is due to heavy biological coating that is provided by Pinus eldarica extract [58]. This

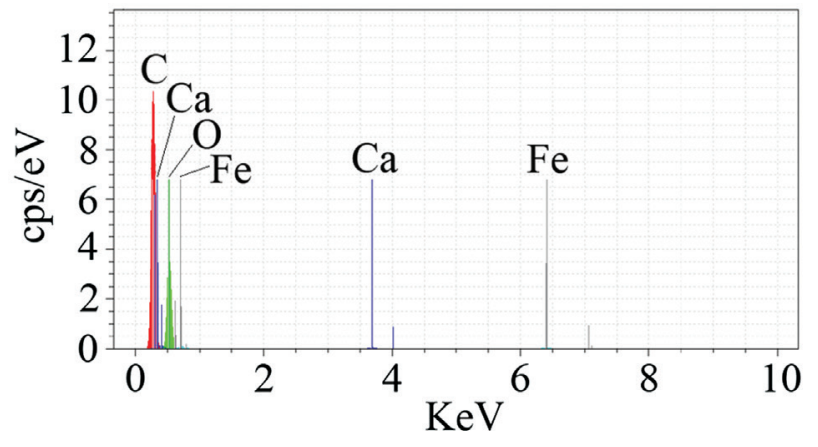

Figure 7: EDS spectrum of the synthesized INPs.

value $(1.87 \%)$ for iron content is one of the least atomic percentage that already were reported.

\section{Conclusions}

Phytochemical compounds from pine tree (Pinus eldarica) needles were successfully utilized as a natural source of reducing and capping agents for the green synthesis of zero valent INPs. Analysis based on the statistical design of experiment indicated that quantity of leaf extract and concentration of iron precursor are the most effective parameters in the green synthesis reaction. Reaction time and temperature showed no significant effects on the nanoparticles fabrication. The prepared particles were intensely surrounded by biologic compounds from leaf extract. Extraordinary capability of Pinus eldarica extract for heavily entrapment of nanoparticles can be introduced as a unique property for the green synthesis of nanoparticles. These findings highlighted the interesting potential of the pine tree needles for application in industrial scale green synthesis of INPs.

Acknowledgments: This study was financially supported by a grant (grant No. 96006) from the Fasa University of Medical Sciences.

\section{References}

[1] Huang L., Weng X., Chen Z., Megharaj M., Naidu R., Green synthesis of iron nanoparticles by various tea extracts: comparative study of the reactivity. Spectrochim. Acta Mol. Biomol., 2014, 130, 295-301.

[2] Wang Z., Yu C., Fang C., Mallavarapu M., Dye removal using iron-polyphenol complex nanoparticles synthesized by plant leaves. Environ. Technol. Innov., 2014, 1, 29-34. 
[3] Xiao Z., Yuan M., Yang B., Liu Z., Huang J., Sun D., Plant-mediated synthesis of highly active iron nanoparticles for $\mathrm{Cr}(\mathrm{VI})$ removal: Investigation of the leading biomolecules. Chemosphere, 2016, 150, 357-364.

[4] Wang Z., Fang C., Megharaj M., Characterization of ironpolyphenol nanoparticles synthesized by three plant extracts and their fenton oxidation of azo dye. ACS Sustain. Chem. Eng., 2014, 2, 1022-1025.

[5] Machado S., Stawiński W., Slonina P., Pinto A., Grosso J., Nouws H., et al., Application of green zero-valent iron nanoparticles to the remediation of soils contaminated with ibuprofen. Sci. Total Environ., 2013, 461, 323-329.

[6] Ebrahiminezhad A., Taghizadeh S., Ghasemi Y., Berenjian A., Green synthesized nanoclusters of ultra-small zero valent iron nanoparticles as a novel dye removing material. Sci. Total Environ., 2017, 15, 1527-1532.

[7] Rajendran K., Karunagaran V., Mahanty B., Sen S., Biosynthesis of hematite nanoparticles and its cytotoxic effect on HepG2 cancer cells. Int. J. Biol. Macromol., 2015, 74, 376-381.

[8] Venkateswarlu S., Kumar B.N., Prasad C., Venkateswarlu P., Jyothi N., Bio-inspired green synthesis of $\mathrm{Fe}_{3} \mathrm{O}_{4}$ spherical magnetic nanoparticles using Syzygium cumini seed extract. Physica B, 2014, 449, 67-71.

[9] Aseri A., Garg S.K., Nayak A., Trivedi S.K., Ahsan J., Magnetic nanoparticles: magnetic nano-technology using biomedical applications and future prospects. Int. J. Pharm. Sci. Rev. Res., 2015, 31, 119-131.

[10] Siddiqi K.S., ur Rahman A., Husen A., Biogenic fabrication of iron/iron oxide nanoparticles and their application. Nanoscale Res. Lett., 2016, 11, DOI:10.1186/s11671-11016-11714-11670.

[11] Wang T., Lin J., Chen Z., Megharaj M., Naidu R., Green synthesized iron nanoparticles by green tea and eucalyptus leaves extracts used for removal of nitrate in aqueous solution. J. Clean. Prod., 2014, 83, 413-419.

[12] Machado S., Pinto S., Grosso J., Nouws H., Albergaria J.T., Delerue-Matos C., Green production of zero-valent iron nanoparticles using tree leaf extracts. Sci. Total Environ., 2013, 445, 1-8.

[13] Ebrahiminezhad A., Bagheri M., Taghizadeh S., Berenjian A., Ghasemi Y., Biomimetic synthesis of silver nanoparticles using microalgal secretory carbohydrates as a novel anticancer and antimicrobial. Adv. Nat. Sci., 2016, 7, DOI:10.1088/20436262/1087/1081/015018.

[14] Ebrahiminezhad A., Zare M., Kiyanpour S., Berenjian A., Niknezhad S.V., Ghasemi Y., Biosynthesis of xanthan gum coated iron nanoparticles by using Xanthomonas campestris. IET Nanobiotechnol., 2017, 151, 684-691.

[15] Kianpour S., Ebrahiminezhad A., Mohkam M., Tamaddon A.M., Dehshahri A., Heidari R., et al., Physicochemical and biological characteristics of the nanostructured polysaccharide-iron hydrogel produced by microorganism Klebsiella oxytoca. J. Basic Microbiol., 2016, 2016, 132-140.

[16] Ebrahiminezhad A., Zare-Hoseinabadi A., Berenjian A., Ghasemi Y., Green synthesis and characterization of zero-valent iron nanoparticles using stinging nettle (Urtica dioica) leaf extract. Green Process. Synth., 2017, 6, DOI:10.1515/gps-2016-0133.

[17] Ebrahiminezhad A., Zare-Hoseinabadi A., Sarmah A.K., Taghizadeh S., Ghasemi Y., Berenjian A., Plant-Mediated Synthesis and Applications of Iron Nanoparticles. Mol. Biotechnol., 2017, 1-15.

[18] Kianpour S., Ebrahiminezhad A., Negahdaripour M., Mohkam M., Mohammadi F., Niknezhad S., et al., Characterization of biogenic Fe (III)-binding exopolysaccharide nanoparticles produced by Ralstonia sp. SK03. Biotechnol. Prog., 2018, 34, 1167-1176.

[19] Ghasemi Y., Rasoul-Amini S., Ebrahiminezhad A., Kazemi A., Shahbazi M., Talebnia N., Screening and isolation of extracellular protease producing bacteria from the maharloo salt lake. Iran. J. Pharm. Sci., 2011, 7, 175-180.

[20] Ghasemi Y., Rasoul-Amini S., Ebrahiminezhad A., Zarrini G., Kazemi A., Mousavi-Khorshidi S., et al., Halotolerant Amylase Production by a Novel Bacterial Strain, Rheinheimera aquimaris. Res. J. Microbiol., 2010, 5, 144-149.

[21] Makarov V.V., Makarova S.S., Love A.J., Sinitsyna O.V., Dudnik A.O., Yaminsky I.V., et al., Biosynthesis of stable iron oxide nanoparticles in aqueous extracts of Hordeum vulgare and Rumex acetosa plants. Langmuir, 2014, 30, 5982-5988.

[22] Ebrahiminezhad A., Barzegar Y., Ghasemi Y., Berenjian A., Green synthesis and characterization of silver nanoparticles using Alcea rosea flower extract as a new generation of antimicrobials. Chem. Ind. Chem. Eng. Q., 2016, 2016, 31-37.

[23] Ebrahiminezhad A., Taghizadeh S., Berenjian A., Heidaryan Naeini F., Ghasemi Y., Green Synthesis of Silver Nanoparticles Capped with Natural Carbohydrates Using Ephedra intermedia. Nanosci. Nanotechnol. Asia, 2016, 6, 1-9.

[24] Luo F., Yang D., Chen Z., Megharaj M., Naidu R., The mechanism for degrading Orange II based on adsorption and reduction by ion-based nanoparticles synthesized by grape leaf extract. J. Hazard. Mater., 2015, 296, 37-45.

[25] Pourmortazavi S., Hajimirsadeghi S., Rahimi-Nasrabadi M., Statistical optimization of condition for synthesis lead sulfide nanoparticles. Mater. Manuf. Processes, 2009, 24, 524-528.

[26] Wang T., Jin X., Chen Z., Megharaj M., Naidu R., Green synthesis of Fe nanoparticles using eucalyptus leaf extracts for treatment of eutrophic wastewater. Sci. Total Environ., 2014, 466, 210-213.

[27] Iravani S., Zolfaghari B., Green Synthesis of Silver Nanoparticles Using Pinus eldarica Bark Extract. Biomed Res. Int., 2013, 2013, DOI:10.1155/2013/639725.

[28] Pourmortazavi S.M., Taghdiri M., Makari V., Rahimi-Nasrabadi M., Procedure optimization for green synthesis of silver nanoparticles by aqueous extract of Eucalyptus oleosa. Spectrochim. Acta Mol. Biomol., 2015, 136, 1249-1254. 
[29] Sadeghi Afjeh M., Fallah Huseini H., Tajalizadekhoob Y., Mirarefin M., Sharifi F., Taheri E., et al., Determination of phenolic compounds in Pinus eldarica by HPLC. J. Med. Plants, 2014, 1, 22-33.

[30] Afsharypuor S., San'aty F., Essential oil constituents of leaves and fruits of Pinus eldarica Medw. J. Essent. Oil Res., 2005, 17, 327-328.

[31] Sarvmeili N., Jafarian-Dehkordi A., Zolfaghari B., Cytotoxic effects of Pinus eldarica essential oil and extracts on HeLa and MCF-7 cell lines. Res. Pharm. Sci., 2016, 11, 476-483.

[32] Huseini H.F., Anvari M.S., Rabbani S., Sharifi F., Arzaghi S.M., Fakhrzadeh H., Anti-hyperlipidemic and anti-atherosclerotic effects of Pinus eldarica Medw. nut in hypercholesterolemic rabbits. DARU J. Pharm. Sci., 2015, 23, DOI:10.1186/s4019940015-40114-40199.

[33] Ghoshoon M.B., Berenjian A., Hemmati S., Dabbagh F., Karimi Z., Negahdaripour M., et al., Extracellular production of recombinant L-Asparaginase II in Escherichia coli: Medium optimization using response surface methodology. Int. J. Pept. Res. Ther., 2015, 21, 487-495.

[34] Ranmadugala D., Ebrahiminezhad A., Manley-Harris M., Ghasemi Y., Berenjian A., Reduced biofilm formation in Menaquinone-7 production process by optimizing the composition of the cultivation medium. Trends Pharma. Sci., 2017, 3, 245-254.

[35] Berenjian A., Mahanama R., Talbot A., Biffin R., Regtop H., Valtchev P., et al., Efficient media for high menaquinone-7 production: response surface methodology approach. N. Biotechnol., 2011, 28, 665-672.

[36] Nagajyothi P., Pandurangan M., Kim D.H., Sreekanth T., Shim J., Green synthesis of iron oxide nanoparticles and their catalytic and in vitro anticancer activities. J. Cluster Sci., 2017, 28, 245-257.

[37] Rajiv P., Bavadharani B., Kumar M.N., Vanathi P., Synthesis and characterization of biogenic iron oxide nanoparticles using green chemistry approach and evaluating their biological activities. Biocat. Agr. Biotechnol., 2017, 12, 45-49.

[38] Ebrahiminezhad A., Rasoul-Amini S., Davaran S., Barar J., Ghasemi Y., Impacts of iron oxide nanoparticles on the invasion power of Listeria monocytogenes. Curr. Nanosci., 2014, 10, 382-388.

[39] Ebrahiminezhad A., Davaran S., Rasoul-Amini S., Barar J., Moghadam M., Ghasemi Y., Synthesis, characterization and anti-Listeria monocytogenes effect of amino acid coated magnetite nanoparticles. Curr. Nanosci., 2012, 8, 868-874.

[40] Ebrahiminezhad A., Rasoul-Amini S., Kouhpayeh A., Davaran S., Barar J., Ghasemi Y., Impacts of amine functionalized iron oxide nanoparticles on HepG2 cell line. Curr. Nanosci., 2015, 11, 113-119.

[41] Ebrahiminezhad A., Najafipour S., Kouhpayeh A., Berenjian A., Rasoul-Amini S., Ghasemi Y., Facile fabrication of uniform hollow silica microspheres using a novel biological template. Colloid. Surface. B, 2014, 118, 249-253.

[42] Ebrahiminezhad A., Varma V., Yang S., Berenjian A., Magnetic immobilization of Bacillus subtilis natto cells for menaquinone-7 fermentation. Appl. Microbiol. Biotechnol., 2016, 100, 173-180.

[43] Ebrahiminezhad A., Varma V., Yang S., Ghasemi Y., Berenjian A., Synthesis and application of amine functionalized iron oxide nanoparticles on menaquinone-7 fermentation: A step towards process intensification. Nanomaterials, 2015, 6, 1-9.

[44] Ebrahimi N., Rasoul-Amini S., Ebrahiminezhad A., Ghasemi Y., Gholami A., Seradj H., Comparative study on characteristics and cytotoxicity of bifunctional magnetic-silver nanostructures: synthesized using three different reducing agents. Acta Metall. Sin., 2016, 29, 326-334.

[45] Hosseinpour-Mashkani S.M., Sobhani-Nasab A., Green synthesis and characterization of $\mathrm{NaEuTi}_{2} \mathrm{O}_{6}$ nanoparticles and its photocatalyst application. J. Mater. Sci. Mater. Electron., 2017, 28, 4345-4350.

[46] Borja J.Q., Ngo M.A.S., Saranglao C.C., Tiongco R.P.M., Roque E.C., Dugos N.P., Synthesis of green zero-valent iron using polyphenols from dried green tea extract. J. Eng. Sci. Technol., 2015, 10, 22-31.

[47] Singh M., Mallick A., Banerjee M., Kumar R., Loss of outer membrane integrity in Gram-negative bacteria by silver nanoparticles loaded with Camellia sinensis leaf phytochemicals: plausible mechanism of bacterial cell disintegration. Bull. Mater. Sci., 2016, 39, 1871-1878.

[48] Mystrioti C., Xanthopoulou T., Tsakiridis P., Papassiopi N., Xenidis A., Comparative evaluation of five plant extracts and juices for nanoiron synthesis and application for hexavalent chromium reduction. Sci. Total Environ., 2016, 539, 105-113.

[49] Ebrahiminezhad A., Taghizadeh S., Berenjiand A., Rahi A., Ghasemi Y., Synthesis and characterization of silver nanoparticles with natural carbohydrate capping using Zataria multiflora. Adv. Mater. Lett., 2016, 7, 122-127.

[50] Ebrahiminezhad A., Taghizadeh S., Ghasemi Y., Green synthesis of silver nanoparticles using Mediterranean Cypress (Cupressus sempervirens) leaf extract. Am. J. Biochem. Biotechnol., 2017, 13, 1-6.

[51] Ebrahiminezhad A., Berenjian A., Ghasemi Y., Template free synthesis of natural carbohydrates functionalised fluorescent silver nanoclusters. IET Nanobiotechnol., 2016, 1-4.

[52] Ebrahiminezhad A., Ghasemi Y., Rasoul-Amini S., Barar J., Davaran S., Impact of amino-acid coating on the synthesis and characteristics of iron-oxide nanoparticles (IONs). Bull. Korean Chem. Soc., 2012, 33, 3957-3962.

[53] Ebrahiminezhad A., Ghasemi Y., Rasoul-Amini S., Barar J., Davaran S., Preparation of novel magnetic fluorescent nanoparticles using amino acids. Colloid. Surface. B., 2013, 102, 534-539. 
[54] Singh R., Misra V., Singh R.P., Synthesis, characterization and role of zero-valent iron nanoparticle in removal of hexavalent chromium from chromium-spiked soil. J. Nanopart. Res., 2011, 13, 4063-4073.

[55] Fan M., Yuan P., Chen T., He H., Yuan A., Chen K., et al., Synthesis, characterization and size control of zerovalent iron nanoparticles anchored on montmorillonite. Chin. Sci. Bull., 2010, 55, 1092-1099.

[56] Üzüm Ç., Shahwan T., Eroğlu A.E., Hallam K.R., Scott T.B., Lieberwirth I., Synthesis and characterization of kaolinitesupported zero-valent iron nanoparticles and their application for the removal of aqueous $\mathrm{Cu}^{2+}$ and $\mathrm{Co}^{2+}$ ions. Appl. Clay Sci., 2009, 43, 172-181.

[57] Machado S., Pacheco J., Nouws H., Albergaria J.T., Delerue-Matos C., Characterization of green zero-valent iron nanoparticles produced with tree leaf extracts. Sci. Total Environ., 2015, 533, 76-81.

[58] Kuang Y., Wang Q., Chen Z., Megharaj M., Naidu R., Heterogeneous Fenton-like oxidation of monochlorobenzene using green synthesis of iron nanoparticles. J. Colloid Interface Sci., 2013, 410, 67-73.

[59] Huang L., Weng X., Chen Z., Megharaj M., Naidu R., Synthesis of iron-based nanoparticles using oolong tea extract for the degradation of malachite green. Spectrochim. Acta Mol. Biomol., 2014, 117, 801-804.
[60] Wang Z., Iron complex nanoparticles synthesized by eucalyptus leaves. ACS Sustain. Chem. Eng., 2013, 1, 1551-1554.

[61] Demir A., Topkaya R., Baykal A., Green synthesis of superparamagnetic $\mathrm{Fe}_{3} \mathrm{O}_{4}$ nanoparticles with maltose: its magnetic investigation. Polyhedron, 2013, 65, 282-287.

[62] Juríková A., Csach K., Miškuf J., Koneracká M., Závišová V., Kubovčíková M., et al., Thermal analysis of magnetic nanoparticles modified with dextran. Acta Phys. Pol. A, 2012, 121, 1296-1298.

[63] Radini I.A., Hasan N., Malik M.A., Khan Z., Biosynthesis of iron nanoparticles using Trigonella foenum-graecum seed extract for photocatalytic methyl orange dye degradation and antibacterial applications. J. Photoch. Photobio. B, 2018, 183, 154-163.

[64] Santra S., Tapec R., Theodoropoulou N., Dobson J., Hebard A., Tan W., Synthesis and characterization of silica-coated iron oxide nanoparticles in microemulsion: the effect of nonionic surfactants. Langmuir, 2001, 17, 2900-2906.

[65] Mohammed Sadiq I., Chandrasekaran N., Mukherjee A., Studies on effect of $\mathrm{TiO}_{2}$ nanoparticles on growth and membrane permeability of Escherichia coli, Pseudomonas aeruginosa, and Bacillus subtilis. Curr. Nanosci., 2010, 6, 381-387.

[66] Wang T., Jin X., Chen Z., Megharaj M., Naidu R., Green synthesis of Fe nanoparticles using eucalyptus leaf extracts for treatment of eutrophic wastewater. Sci. Total Environ., 2014, 466-467, 210-213. 